\title{
KODIFIKASI SASTRA ARAB PERIODE KLASIK (JAHILY)
}

\author{
Marzuki Mustamar
}

Dosen Jurusan Bahasa dan Sastra Arab,

Fakultas Humaniora dan Budaya, Universitas Islam Negeri (UIN) Malang.

Jalan Gajayana No. 50 Telepon (0341) 551354, Faksimile (0341) 572533 Malang 65144

\begin{abstract}
"Ayyam al-Arab" and "al-Ansab" which recorded, both in the form of genre prosa and genre poetry is an authentic evidence that show jahiliyah society have produced literary works. Those two sources were dig up by hammad al-Rawiyyah when he codified jahili's literary works.
\end{abstract}

\section{Key words}

Codification, Jahili's literary

\section{Pendahuluan}

Secara sosiologis sastra merupakan refleksi lingkungan budaya dan merupakan satu teks dialektis antara pengarang dan situasi sosial yang membentuknya atau merupakan penjelasan suatu sejarah dialektik yang dikembangkan dalam karya sastra. Sehubungan dengan ini sering dikatakan bahwa syair merupakan antologi kehidupan masyarakat Arab (Diwan al-'Arab) (Khafajy, 1973:195). Artinya, semua aspek kehidupan yang berkembang pada masa tertentu tercatat dan terekam dalam sebuah karya sastra (syair).

Kalangan penyair bukanlah satu-satunya komunitas yang amat peduli kepada pendidikan syair. Secara umum anggota masyarakat (kabilah) juga memiliki kepedulian yang sama. Untaian kata-kata dalam syair bagi masyarakat Arab bukanlah semata-mata bunyi yang disuarakan lisan yang tanpa makna (absurd), melainkan sarana yang 
ampuh (sakral) untuk membakar semangat, menarik perhatian, dan meredam emosi yang bergejolak di tengah kehidupan masyarakat. Bisa dipahami kalau masyarakat meyakini bahwa para penyair memiliki pengetahuan magis (Amin, 1975:55) yang terekspresikan dalam syair dan keberadaan syair ini sangat diperhatikan dan dipatuhi substansinya karena ia merupakan realitas kehidupan kabilah. Nampaknya inilah alasan yang diyakini masyarakat ketika mereka menempatkan para penyair pada posisinya yang terhormat (Khafajy, 1973:195). Mereka menjadi simbol kejayaan suatu kabilah dan penyambung lidah yang mampu melukiskan kebaikan dan kemenangan kabilah sebagaimana mereka mampu mendeskripsikan kejelekan dan kekalahan perang yang diderita kabilah lain. Itulah di antara beberapa sebab mengapa syair pada periode jahili didominasi oleh jenis madah (pujian/ode) dan hija' (ejekan/satire) (Al-Iskandary, 1952:65).

\section{Eksistensi Sastra Arab Jahily}

Seorang pemikir Islam dan juga seorang sastrawan, adalah Thaha Husein dengan sejumlah argumen untuk membangun teorinya melalui pendekatan sosiologis/ekstrinsik- merasa keberatan ("menolak") akan keberadaan sastra Arab jahili. Dari hasil penelitiannya ia mengajukan tiga tesis yang amat tajam. Tesis pertama, sebagian besar dari apa yang disebut syair Arab jahili bukan lahir pada masa jahiliyah, melainkan diciptakan pada zaman Islam (Husein, tt:65). Tesis kedua, adanya kesenjangan antara gaya intelektual yang ada pada sastra (syair) jahili dan kondisi intelektual masyarakat Arab jahiliyah (Husein, tt:67). Tesis ketiga, keberadaan syair lebih awal dari pada prosa, karena prosa membutuhkan bahasa rasional yang amat perlu kepada ketrampilan dan kepandaian menulis. Dimaklumi, pada saat itu masyarakat jahiliyah adalah masyarakat ummi (tidak bisa membaca dan menulis) (Husein, tt:326-329).

Munculnya statemen di atas, membuat ulama konservatif Mesir marah, ia harus dikeluarkan dari lingkungan akademik Universitas alAzhar dan bahkan ia dituduh "kafir". Baik dalam bentuk buku maupun 
tulisan lepas, kritik arus balik bermunculan guna mengkritisi pikiranpikiran dan teori-teori yang dibangun Thaha Husein. Mereka khawatir metode kritik yang ditransformasi dari "Barat" itu akan menggugurkan dasar-dasar struktur tradisional penafsiran al-Qur’an dan pengajaran sastra Arab.

Menurut sebagian sastrawan, sastra Arab telah ada beberapa abad sebelum Masehi. Akan tetapi karya sastra (syair) tersebut yang ada sampai sekarang adalah karya sastra yang lahir dua abad sebelum Islam. Hal ini bukan berarti bahwa sebelum itu orang Arab tidak mengenal sastra, tetapi yang dapat direkam hanya sampai pada zaman Muhalhil saja. Oleh sebab itu ia dianggap sebagai perintis pertama sastra Arab jahiliyah.

Masyarakat Arab jahiliyah dikenal sebagai masyarakat yang tidak bisa membaca dan menulis (ummi). Maka satu-satunya yang dapat diandalkan ketika mereka menerima informasi adalah kekuatan hafalan. Di samping itu, juga adanya faktor eksternal yang sangat dominan, yaitu mereka terdorong untuk menghafal al-Ayyam (peristiwa penting) dan al-Ansab (genealogi) yang menjadi kebanggaan. Dua jenis pengetahuan ini banyak tersimpan dalam karya sastra baik berupa syair maupun berupa prosa (Yatim, 1997:29-39). Maka amat wajar kalau pada masa jahiliyah karya sastra disosialisasikan melalui sarana tradisi oral. Dengan kata lain, seorang penyair meriwayatkan gubahan syair kepada generasi penyair lainnya, kemudian penyair tersebut meriwayatkannya kepada penyair berikutnya. Pada akhirnya proses penyampaian semacam ini mengenal istilah riwayah yang sekaligus terkait dengan sanad (transmisi), matan (materi/isi), dan al-`ardh wa al-ada (penyampaian).

\section{Karakteristik Sastra Arab Jahily}

Seperti yang dikemukakan Syauqi Dhaif, ada beberapa persyaratan dalam penyampaian (al-'ardh wa al-ada') sebuah karya sastra. Pertama, al-tamatstsul yaitu memberikan contoh pengungkapan karya sastra dengan susunan yang baik. Kedua, al-diqqah yaitu sifat 
ketelitian dalam penyampaian karya sastra. Ketiga, al-ada`al-sadid, yaitu penyampaian yang benar dengan memberikan penjelasan beberapa kata asing dan penggunaan gaya bahasa dalam karya sastra (Dhaif, tt:7).

Adapun sanad dalam sastra terdiri dari orang-orang yang tsiqah (kapasitas intelektualnya dapat dipercaya), dan orang-orang yang semasa (syahadah al-zaman). Hal ini dilakukan supaya informan dan yang menerima -rawi- bisa bertemu langsung (liqa'), dan harus disampaikan secara lisan/oral (musyafahah) yang diikuti dengan ungkapan haddatsana atau akhbarana (Dhaif, tt:163). Bahkan lebih dari itu, kepekaan pendengaran dan ketajaman pandangan menjadi persyaratan bagi seorang perawi (Hasan, 1990:175).

Apabila terjadi perselisihan di antara dua riwayat, maka solusi yang ditawarkan adalah tarjih, yaitu memilih di antara keduanya yang lebih kuat dan yang dapat dipercaya. Maka tidak mengherankan kalau Abu al-Farj melakukan hal yang sama seperti yang dilakukan Muhadditsin yaitu al-Ta'dil wa al-Tarjih (mengkritisi para perawi yang dianggap jujur dan dusta) (Al-Rafi'i, 1974:287). Dengan demikian, maka informasi yang diterima menjadi valid (shahih) dan dapat dipertanggungjawabkan.

Ada beberapa faktor yang menyebabkan terjadinya perbedaan riwayat dalam karya sastra. Di antaranya; 1) para perawi berpegang teguh kepada tradisi hafalan, 2) untuk memperkuat argumentasi, 3) terjadinya kesalahan dalam ucapan, dan 4) bertambahnya jumlah perawi (Al-Rafi'i, 1974:327).

Periwayatan karya sastra memiliki dua tujuan yang urgen. Pertama, karya sastra merupakan pangkal atau rujukan periwayatan ilmu pengetahuan. Maka adanya riwayat sastra berfungsi untuk: 1). Menghindari pembengkakan riwayat, misalnya dalam bidang pembacaan al-Qur'an, Hadits, berita, bahasa dan sebagainya yang pada akhirnya akan berakibat munculnya informasi-informasi pubrikatif (palsu). 2). Mengetahui penjelasan dan maksud dari bidang-bidang di atas. Kedua, karya sastra dapat dijadikan bukti (syahid) dan contoh (AlRafi'i, 1974:401). 
Hammad al-Rawiyah (w. $155 \mathrm{H}$ ) adalah orang yang pertama kali (pioner) yang mengkodifikasi syair-syair Arab, dan karena keluasannya ia mendapat gelar atau sebutan dengan istilah bi al-rawiyah (orang yang profesional dalam periwayatan). Ia hidup di Basrah pada masa khalifah Marwan bin al-Hakam (khilafah Umayah). Metode al-sima` (mendengar) yang dikembangkannya juga disosialisasikan oleh muridnya yang bernama Khalf al-Ahmar (w. $180 \mathrm{H}$ ) di Kufah. Walaupun keduanya sangat berjasa dalam bidang kesusastraan, tetapi belakangan banyak yang mengkritisi dan menuduhnya sebagai orang yang memanipulasi gaya bahasa sastra (sastra Arab jahili) (Brockelmann, tt:67).

Menanggapi kritikan di atas, Syauqi Dhaif menyatakan dengan tegas bahwa keduanya termasuk orang tsiqah dan orang yang memiliki potensi dalam mengungkapkan fenomena kehidupan jahiliyah yang sebenarnya. Berbeda dengan al-A`sya, al-Mufaddhal al-Dhabi, dan alAshma i yang dapat digolongkan kepada kelompok rawi pubrikatif (palsu/dusta) (Brockelmann, tt:3).

Sekalipun mereka termasuk para perawi yang tsiqah kita tidak akan menemukan satu riwayat pun yang sanadnya benar-benar bersambung kepada penyair jahili. Namun perlu diketahui, bahwa mereka adalah generasi pertama yang mengetahui sejarah periwayatan. Mereka lebih banyak meriwayatkan tentang situasi kehidupan jahiliyah dari pada orang-orang yang hidup semasa (Al-Rafi'i, 1974:288).

Mengutip Thaha Husein, Husein al-Hajj Hasan mengatakan, ada beberapa faktor yang menyebabkan terjadinya pemalsuan dan pencurian (al-wadh'u wa al-nahl) karya sastra. Di antaranya; 1) faktor politik, 2) faktor agama, 3) faktor cerita, 4) faktor nasionalisme, dan 5) faktor perawi (Hasan, 1990:100-101).

Para sastrawan, kritikus sastra, dan sejarawan dalam memberikan penilaian keshahihan sanad dan matan karya sastra pada prinsipnya mengikuti jejak atau metodologi seperti yang dikembangkan para ahli Hadits. Misalnya, tanda-tanda kepalsuan dalam sanad Hadits di antaranya: 1). Pengakuan perawi bahwa dirinya adalah pendusta, atau membuat-buat berita. 2). Adanya bukti kepalsuan, misalnya perawi 
meriwayatkan dari gurunya tetapi ia tidak pernah bertemu, atau meriwayatkan dari gurunya tetapi ia lahir setelah sang guru meninggal, atau masih berusia muda yang tidak menyaksikan kematian gurunya, dan lain-lain. 3). Seorang perawi yang dikenal pendusta dalam periwayatan hadits. 4). Adanya beberapa bukti yang menetapkan bahwa perawi tersebut tidak memiliki kredibilitas.

Sedangkan tanda-tanda kepalsuan dalam matan Hadits di antaranya: 1) Bahasanya lemah, tidak fasih dan baligh. 2) Menyalahi kaidah universal dalam rasio, hukum, dan akhlak. 3) Menyalahi kaidah kedokteran. 4) Menyimpang dari aqidah, hukum, sunnatullah, al-Qur`an, sunnah Nabi. 5). Bertentangan dengan hakikat sejarah. 6) Seorang diri dalam periwayatan. 7) Berlebih-lebihan dalam periwayatan. 8) Ada sebagian kalimat yang terbuang (Hasan, 1990:114).

\section{Diwan (Antologi) Para Sastrawan Arab}

Beberapa diwan (antologi) yang memuat karya para sastrawan masa jahiliyah dan masa Islam banyak dinisbatkan kepada para rawi Basrah dan Kufah. Karena mereka sangat memperhatikan kriteriakriteria ketsiqahan seorang rawi. Misalnya al-Ashma 'i, ia menulis enam diwan; 1) diwan Umru`al-Qais, 2) diwan al-Nabighah, 3) diwan Zuhair, 4) diwan Tharafah, 5) diwan 'Antarah, dan 6) diwan 'Alqamah bin `Abadah.

Adapun diwan (kodifikasi sastra) yang dapat dijadikan rujukan dan referensi adalah diwan Dzi al-Rummah. Dalam diwannya ia menyebutkan dua macam riwayat, masing-masing mempunyai dua jalur:

Riwayat pertama; dari Tsa'lab dari Abi Nashr Ahmad bin Hatim (murid al-Ashma`i). Jalur pertama; dari Abu al-Husein `Ali bin Ahmad al-Muhalbi (w. 385 H) dari Abi al-'Abbas Ahmad bin Muhammad bin Wallad (w. 332 h) dari ayahnya Muhammad bin Wallad (w. 298 H) dari Tsa lab dari Abi Nashr Ahmad bin Hatim. Jalur kedua; dari Ja'far bin Syadzan al-Qummi dari Abi 'Umar al-Zahid (pembantu Tsa'lab) dari Tsa 'lab dari Abi Nashr Ahmad bin Hatim. 
Riwayat kedua; dari Ibrahim bin al-Mundzir (w. 236) dari Aswad bin Dhab an dari Dzi al-Rummah. Jalur pertama; dari Abu al-Husein `Ali bin Ahmad al-Muhalbi dari Ibrahim bin 'Abdullah (w. $355 \mathrm{H}$ ) dari Ahmad bin Ibrahim dari Hilal al-Raqi (w. 280 H) dari Ibrahim bin alMundzir dari Aswad bin Dhab an dari Dzi al-Rummah. Jalur kedua; dari Abu 'Imran bin Rabbah dari Ibrahim bin 'Abdullah dari Ahmad bin Ibrahim dari Hilal al-Raqi dari Ibrahim bin al-Mundzir dari Aswad bin Dhab an dari Dzi al-Rummah.

Diwan di atas dijadikan rujukan Abu Ya`qub (w. 423 H ). Dalam biografinya, Ibn Khillikan (Syamsyani, 1990) mengomentari mengenai diwan yang dipegang Abu Ya'qub, ia berkata, "Referensi klasik yang memuat syair-syair Arab dan peristiwa-peristiwa penting di Mesir banyak diriwayatkan dari Abu Ya`qub, ia adalah seorang rawi yang alim" (Dhaif, tt:165-167).

Di samping diwan di atas, juga ada sejumlah rawi sastra ternama yang telah mengkodifikasi sastra Arab. Mereka ialah;

1. Abu `Amr al-Syaibani (w. $213 \mathrm{H}$ ), ia mengumpulkan syair-syair sebanyak seratus delapan puluh kabilah. Dan ia menulis lima diwan, yaitu diwan Umru' al-Qais, al-Huthaiah, Labid, Duraid bin al-Shimmah, dan al-A`sya.

2. Al-Ashma $\mathrm{i}$ (w. $215 \mathrm{H}$ ), ia menulis beberapa diwan, di antaranya diwan Umru`al-Qais, al-Huthaiah, Labid, al-Nabighah, al-A`sya, Bisyr bin Abi Hazim, al-Muhalhil, al-Musayyab, dan alMutalammis.

3. Ibn al-Sikkit (w. $245 \mathrm{H}$ ), ia menulis lebih dari dua puluh diwan, di antaranya diwan Umru` al-Qais, al-Huthaiah, Labid, al-A`sya, Bisyr bin Abi Hazim, al-Muhalhil, al-Mutalammis, al-Musayyab, 'Adi bin Zaid, al-Khansa', Qais bin al-Khatim, Tamim bin Muqbil, dan lain-lainnya.

4. Abu al-Farj al-Ashfahani (w. $245 \mathrm{H}$ ), ia menulis sepuluh kitab, yaitu kitab Fi Akhbar al-Qabail Wa Ansabuha, kitab al-Akhbar Wa al-Nawarid, kitab Majmu`al-Akhbar Wa al-Atsar, kitab Ayyam al'Arab, kita al-Aghani, dan lain-lain. 
Proses penulisan dawawin atau kitab-kitab di atas melalui salah satu dari beberapa metode antara lain: 1). Metode dikte, yaitu guru membacakan kepada murid. 2). Metode menulis, yaitu murid menulis setelah mendengar dari guru. 3). Memindahkan dari beberapa kitab yang telah ada. 4). Seorang guru menulis sendiri (Hasan, 1990:87).

Melihat keberadaan sastra Arab jahili, seorang pemikir Islam dan juga seorang sastrawan bernama Thaha Husein dalam karya monumentalnya Fi al-Adab al-Jahili mengajukan tiga tesis yang sangat keras. Dengan sejumlah argumen dan teori "keragu-raguan" yang dikembangkan pada akhirnya ia berkesimpulan untuk menolak keberadaan sastra Arab jahili.

Tesis pertama, sebagian besar dari apa yang disebut sebagai syair jahili itu bukan lahir pada masa jahiliyah, melainkan diciptakan pada masa Islam. Terjemahan redaksinya berbunyi sebagai berikut:

Sebagian besar dari karya sastra yang disebut-sebut sebagai sastra (syair) jahiliyah, sedikitpun tidak berasal dari zaman jahiliyah, melainkan muncul setelah zaman Islam, karya tersebut lebih banyak menggambarkan kehidupan dan keinginan kaum muslim dari pada kehidupan jahiliyah. Saya hampir tidak meragukan bahwa hanya sebagian kecil saja sisa dari karya sastra jahilyah yang benar-benar otentik. Karya-karya tersebut hanya manipulasi rawi, rekayasa orang Arab badui, produk linguis, pubrikasi pedongeng, dan argumentasi para mufassir, muhaddits, dan teolog.(Husein, tt:65)

Tesis kedua, adalah adanya kesenjangan antara gaya intelektual yang ada pada sastra (syair) jahili dengan kondisi intelektual masyarakat Arab jahiliyah. Terjemahan redaksinya berbunyi sebagai berikut: 
Dilihat dari aspek bahasa dan seni bahwa syair yang disandarkan kepada Umru' al-Qais, al-A 'sya atau sastrawan lainnya tidak mungkin milik mereka dan diciptakan sebelum turunnya alQur'an (Husein, tt:326).

Tesis ketiga, keberadaan syair lebih awal dari pada prosa, karena prosa membutuhkan bahasa rasional yang amat perlu kepada ketrampilan dan kepandaian menulis. Dan dimaklumi, pada saat itu masyarakat jahiliyah adalah masyarakat ummi (tidak bisa membaca dan menulis). Terjemahan redaksinya berbunyi sebagai berikut:

Prosa adalah bahasa rasional, fenomena intelektual, pengaruh kemauan terhadap prosa lebih besar dari pada terhadap syair. Demikian pula pengaruh cara berfikirnya. Jika kita mencari sejarah prosa Arab jahiliyah berdasarkan teori tersebut maka sangat sulit jika tidak mustahil- untuk memperoleh sesuatu yang berharga. Karena kita terpaksa bersikap terhadap keberadaan prosa jahili, sebagaimana sikap kita menanggapi keberadaan syair jahili. Kita (hampir) tidak mengetahui sejarah penulisan di kalangan orangorang Muhdhar, kita terpaksa untuk mengasumsikan sebagian besar genre prosa jahili yang disandarkan kepada orang-orang Mudhar itu sebelum Islam (Husein, tt:326-329).

Keberatan Thaha Husein untuk menjadikan syair jahili sebagai referensi untuk mengetahui kehidupan masyarakat jahiliyah, di samping deskripnya tidak fair dan tidak realistis, secara historis memang sangat beralasan, sebab dalam perjalanan sejarahnya yang panjang, dan melewati peristiwa-peristiwa penting di Arab, syair tersebut boleh jadi dipalsukan.

Sebagaimana diketahui bahwa salah satu ilmu yang dibanggakan orang Arab pra-Islam adalah syair. Namun setelah Islam datang perhatian mereka menjadi berkurang disebabkan karena 
kesibukan melakukan jihad dalam peperangan, khususnya dengan Persia dan Romawi.

Setelah daerah Islam meluas dan banyak daerah yang ditundukkan, maka keinginan untuk meriwayatkan syair tumbuh kembali. Tetapi dalam semangat yang baru ini, mereka dihadapkan kepada persoalan baru pula, yaitu tidak adanya sumber-sumber, baik dalam bentuk buku maupun dalam bentuk kumpulan syair yang tercatat. Sementara para penyair sudah banyak yang meninggal. Bukankah ini merupakan penyebab adanya kecenderungan sekelompok orang untuk mengklaim syair yang diciptakan pada zaman Islam sebagai syair jahili.

Dengan teori kritik sastranya, Thaha Husein mencurigai akan keontetikan syair jahili yang dianggap sebagai syair jahiliyah itu tidak merefleksikan perbedaan linguistik yang terdapat di jazirah Arab, seperti yang digambarkan al-Qur'an. Setelah melalui pengujian dalam penelitiannya sampailah ia pada kesimpulan bahwa dalam syair-syair jahili itu terdapat inkonsistensi antara bahasa, gaya, dan ide dengan kondisi jazirah Arab yang pada saat itu masih belum bersatu. Hanya ada beberapa syair saja yang dapat disebut syair jahili yang otentik.

Atas keberatan Thaha Husein dalam menjadikan sastra (syair) sebagai rujukan untuk mengetahui kehidupan masyarakat jahiliyah, terbitlah beberapa buku karya ulama (intelektual) untuk mengkritisi pikiran-pikiran Thaha Husein. Di antaranya ialah al-Ru'yah alHadhariyah Wa al-Naqdiyah Fi Adab Thaha Husein, karya Dr. Yusuf Nur 'Iwadh, dan al-Syi'r al-Jahili, karya Muhammad `Abd al-Mun im Khafaji. Mereka menjawab panjang lebar, dengan argumen-argumen yang rasional dan bisa dipertanggungjawabkan. Namun Penulis dapat menyimpulkan sebagai berikut:

Pertama, tidak diragukan bahwa karya sastra selalu terkait dengan kehidupan sosial. Akan tetapi sangat keliru, kalau dikatakan bahwa karya sastra mencakup seluruh aspek kehidupan sosial, apalagi membicarakannya secara rinci. 
Kedua, ada pendapat yang mengatakan bahwa bahasa Arab fusha resmi menjadi bahasa bangsa Arab setelah Islam lahir, bukan sebelumnya. Jika statemen ini diterima, maka bagaimana bisa dipahami bahwasanya al-Qur'an diturunkan dengan bahasa kaumnya. Dan apakah nilai urgensinya tantangan al-Qur'an terhadap bangsa Arab jika al-Qur'an diturunkan bukan dengan bahasa kaumnya ? Bagaimana bisa terjadi al-Qur'an sebagai kitab dakwah, kitab hukum, dan kitab undangundang bagi kaum yang tidak memiliki bahasa yang baik (fusha)? ('Iwadh, tt:104-114).

Ketiga, jika bangsa terdahulu seperti Persia, India, dan Mesir Kuno memiliki karya sastra (prosa) beberapa abad sebelum Masehi, mengapa bangsa Arab (masyarakat jahiliyah) tidak memiliki genre prosa setelah lima abad Masehi? Kalau persoalannya masyarakat jahiliyah itu ummi, perlu diketahui bahwa ketrampilan menulis itu dibutuhkan pada saat kodifikasi, bukan pada awal perkembangannya (Al-Khafajy, 1973:129-133).

Barangkali apa yang diinginkan Thaha Husein tersebut agar umat Islam tidak memandang sastra Arab jahili dan penafsiran para ulama sebagai sesuatu yang sakral (tidak boleh digugat). Ketika umat Islam kembali kepada ajaran yang sebenarnya, yaitu al-Qur'an dan Hadits maka akan terjadi hubungan dialogis yang tidak putus. Dengan demikian dalam tubuh umat Islam selalu ada dinamika, kreativitas, dan produktifitas yang bisa membawa kemajuan. Sebagaimana yang dikatakan Syahrin Harahap:

Sesungguhnya kalau dikaji secara filosofis, sebenarnya yang diinginkan Thaha Husein itu bukan hanya sekedar mempraktekkan metode kritik sejarah dan semantik yang diperolehnya dari Barat. Melainkan ia terdorong agar umat Islam tidak memandang sakral bahasa dan sastra Arab (syair jahili), dan juga tidak menganggap sakral penafsiran para ulama dalam berbagai kajian keislaman, termasuk kehidupan pra-Islam. Ia mengajak umat Islam agar 
kembali kepada ajaran dasar Islam (al-Qur'an dan Hadits), dan selanjutnya melakukan ijtihad (Harahap, 1994:138).

\section{Penutup}

Walaupun masyarakat jahiliyah dikenal dengan sebutan masyarakat "ummi", yaitu masyarakat yang tidak bisa membaca dan menulis hal ini tidak memberikan justifikasi bahwa mereka tidak melahirkan karya sastra. Ada dua jenis pengetahuan yang bisa dijadikan bukti autentik tentang keberadaan sastra arab jahili, yaitu Ayyam al`Arab dan al-Ansab (genealogi). Ayyam al- 'Arab berisi tentang peristiwaperistiwa (peperangan) bersejarah yang menimpa masyarakat jahiliyah, sedangkan al-ansab membicarakan silsilah keturunan. Dua jenis pengetahuan ini banyak dimuat dalam karya sastra, baik genre prosa maupun syair. Secara emosional mereka dituntut untuk menghafalnya, karena kemenangan dalam peperangan dan memiliki keturunan yang mulia menjadi kebanggaan tersendiri di tengah kehidupan masyarakat (kabilah). Rupanya faktor inilah yang mendukung kekuatan hafalan mereka ketika menerima informasi (karya sastra) yang disampaikan secara oral (lisan).

Hammad al-Rawiyah (w. $155 \mathrm{H}$ ) adalah orang pertama kali (pioner) mengkodifikasi karya sastra Arab (jahili). Namun yang lebih sempurna kumpulan karya sastra Arab banyak ditulis Dzi al-Rummah. Kemudian diwan ini dijadikan referensi dan rujukan oleh para pencinta sastra lainnya seperti Abu `Amr al-Syaibani (w. 213 H), Al-Ashma`i (w. 215 H), Ibn al-Sikkit (w. 245 H), Abu al-Farj al-Ashfahani (w. 245 H). $\square$

\section{DAFTAR PUSTAKA}

'Athawy, Ali Najib. 1994. Dzu al-Rummah Sya'ir al-Thabi'ah wa al-Hubb. Bairut: Dar al-Kutub al-'Ilmiyyah. 
'Iwadh, Yusuf Nur. Tanpa tahun. Al-Ru'yah al-Hadhariyyah wa alNaqdiyyah fii Adab Thaha Husain. Bairut: Dar al-Qalam.

Ahmad, Amin. 1975. Fajr al-Islam. Tanpa Tempat: Tanpa tahun.

Al-Iskandary, Ahmad dan Musthofa Inany. 1952. Al-Wasith fii al-Adab al'Araby wa Tarikhuhu. Kairo: Dar al-Ma'arif.

Al-Rafi'i, Musthafa Shadiq. 1974. Tarikh Adab al-'Arab. Bairut: Dar alKitab al-'Araby.

Brochelmann, Carl. Tanpa tahun. Tarikh al-Adab al-'Araby. Terjemahan Abdul Hakim al-Najjar. Bairut: Dar al-Ma'arif.

Dhaif, Syauqy. Tanpa tahun. Al-Bahts al-Adaby Thabi'atuhu Manahijuhu Ushuluhu Mashadiruhu. Kairo: Dar al-Ma'arif.

Harahap, Syahriin. 1994. Al-Qur'an dan Sekuralisme: Kajian Kritis terhadap Pemikiran Thaha Husein. Yogyakarta: Tiara Wacana.

Hasan, Husein al-Hajj. 1990. Adab al-'Arab fii Ashr al-Jahiliyyah. Bairut: Tanpa Penerbit.

Husein, Thaha. Tanpa tahun. Fii al-Adab al-Jahily. Kairo: Dar al-Ma'arif.

Khafajy, Muhammad Abdul Mun'im. 1973. Al-Syi'r al-Jahily. Bairut: Dar al-Kitab.

Syamsyani, Hasan. 1990. Ibnu Khillikan. Bairut: Dar al-Kutub al'Ilmiyyah.

Yatim, Badri. 1997. Historiografi Islam. Jakarta: Logos. 